\title{
The Effect of Different Modes of English Captioning on EFL learners' General Listening Comprehension: Full text Vs. Keyword Captions
}

\author{
Sorayya Behroozizad (Corresponding author) \\ Department of English Language Teaching, Maragheh branch, Islamic Azad University, Maragheh, Iran \\ E-mail: Sorayyabehroozi@yahoo.com \\ Sudabeh Majidi \\ Department of English Language Teaching, Maragheh branch, Islamic Azad University, Maragheh, Iran
}

\author{
Doi:10.7575/aiac.alls.v.6n.4p.115 \\ URL: http://dx.doi.org/10.7575/aiac.alls.v.6n.4p.115
}

Received: 28/03/2015

Accepted: 02/06/2015

\begin{abstract}
This study investigated the effect of different modes of English captioning on EFL learners' general listening comprehension. To this end, forty five intermediate-level learners were selected based on their scores on a standardized English proficiency test (PET) to carry out the study. Then, the selected participants were randomly assigned into two experimental groups (full-captions and keyword-captions) and one control group (no-captions). Research instrumentation included a pre-test and a post-test following an experimental design. Participants took a pre-test and a post-test containing 50 multiple-choice questions (25question for pre-test and 25 question for post-test) selected from a standard listening test PET, and also 15 treatment sessions. The findings showed significant differences among fullcaptions, keyword-captions, and no-captions in terms of their effect on learners' general listening comprehension. This study provided some pedagogical implications for teaching listening through using different modes of captions.
\end{abstract}

Keywords: Caption, full caption, keyword caption, listening comprehension

\section{Introduction}

Listening, the most frequently used form of language skill, plays a significant role in daily communication and also in educational process. Mendelsohn (1994) found that of the total time spent on communication 45-50\% is devoted to listening, $25-30 \%$ to speaking, $11-16 \%$ to reading, and $9 \%$ to writing. The first language mode that children acquire is listening (Krashen, 1985). When it is time for children to learn to read, they still have to listen so that they gain knowledge and information to follow directions. In the classroom context, students have to spend most of the time listening to what the teacher says, for example, giving lectures, asking questions, or telling directions. It is worth mentioning that nearly $90 \%$ of the class time in high school and university is spent in listening to discussion and lectures as estimated by Taylor (1964). Listening is one of the most important language skills in other words the "Cinderella skill" in second language learning (Nunan, 1997, p. 47).

In spite of its importance, listening has long been the neglected skill in ESL/EFL teaching. Long ago, listening comprehension was considered as a passive and receptive activity, meriting little research and pedagogical attention (Jung, 2003; Thompson \& Rubin, 1996; Vandrgrift, 2004). Traditionally, many teachers assumed that listening is a natural skill that is developed by children on their own through exposure and does not require teaching and instruction. The focus of earlier listening comprehension materials was mainly on testing students' ability to listen to oral discourse and then answer comprehension questions based upon the incoming information (Carrier, 2003; Field, 1998). However, in recent years there has been a great deal of attention devoted on L2 listening ability because of its perceived importance in teaching and language learning.

With the emergence of technology, language learning environments have moved into a new era of teaching listening, which were based on the use of authentic audiovisual materials (Vandergrift, 2011). In recent years, with the increasing access to technologies such as, TV, DVD player, video equipment and more recently, the computers, many teachers have found more opportunities to use audio-visual teaching materials at all levels of foreign language teaching, and they have frequently used them effectively in language classes (Meskill, 1996). Satellite programs, feature films, talk shows and so forth have become a daily part of people's life and the request for improvement of listening comprehension has arisen (cited in Latifi et al, 2011, p. 19). However, soon it became clear that without the use of a help option, understanding these ungraded materials is very hard, as most learners don't have enough linguistic knowledge (Flowerdew \& Miller, 2005). Based on the view of Field (2004) in order to overcome this gap, the use of subtitles and captions has been suggested since they could help learners by allowing dual processing of input. Captions allow learners to use their reading skill to improve their aural comprehension (Garza, 1991).

Captioning and subtitling were used in foreign language instruction for the first time in the 1980s. The purpose was to 
increase learners' attention and motivation, decrease the confusion and anxiety, give learners consistent stability of their understanding of what was heard (Burger, 1989; Froehlich, 1988; Grimmer, 1992; Vanderplank, 1988). Some empirical studies (Borras \& Lafayette, 1994; Danan, 2004; Garza, 1991; Markham \& Peter, 2003) have confirmed that combining captions with audio-visual materials is an effective instructional tools to enhance the listening and reading comprehension of a second language as learners can confirm the information they hear by the way of the support provided by the captions. Captions can facilitate second language learning by helping learners visualize what they hear, particularly if the input is a little beyond their linguistic capacity (Danan, 2004). Furthermore, captions might be conductive to language comprehension by facilitating additional cognitive processes, such as greater depth of oral-word processing (Bird \& Williams, 2002).

In the late 1999's Guillory (1998) investigated the effects of keyword captions to authentic French video on learner comprehension. He compared the use of full text captions, keyword captions, and no captions on comprehension of two educational videos. The results of the experiment showed that the full captions group outperformed the keyword captions group and no captions group. This created a rational for the use of captions. This study is based on the Guillory (1998) and Park (2004) research project frameworks and investigated the effect of different modes of captioning on listening comprehension. It is worth mentioning that the researcher took the same keyword determination procedure as Guillory (1998) and Park (2004) procedure. In this paper it is important to distinguish the term captions from subtitles. Captions "refer to on-screen text in a given language combined with a soundtrack in the same language", while subtitles "refer to on-screen text in the native language of the viewers that accompany the second language soundtrack of the video materials "(Markham \& Peter, 2003, p. 332).In this study the two terms, subtitle and captions are used interchangeably, with regard to this point that, our interpretation of subtitle in this study is English subtitle or captions. Originally, captions were intended as a service for the deaf and hard-of- hearing but they have long been used in language situations.

While most of studies have investigated the benefits of captions, and its effect (presence and absence of captions) on listening comprehension, this study aimed to investigate the effect of different modes of captioning on general listening comprehension of Iranian EFL learners.

\subsection{Research Questions}

The present study intends to answer the following research questions:

1. Does providing full captions for films (animated cartoon movies) have any significant impact on students' general listening comprehension?

2. Do providing keyword captions for films (animated cartoon movies) have any significant impact on students' general listening comprehension?

3. Which modes of captioning have the most significant impact on students' general listening comprehension?

\section{Method}

\subsection{Participants}

The participants of this study were 45 intermediate level learners who were selected from a population of 58 EFL learners studying English as a foreign language in one of the institutes in Shahindej, West Azarbayjan. The learners were selected based on their scores on PET (Preliminary English Test) test. Then, the selected participants were randomly assigned into two experimental groups, i.e., full caption (Group A) and keyword caption (Group B), and one control group, i.e., none caption (Group C), each group including 15 learners. All of the participants were female and their national language was Farsi. The participants aged from 15 to 18 studying the Four Corners series (Jack C. Richards and David Bohlke, 2012). The learners had studied English as a foreign language for almost three years at institutions in Shahindej.

\subsection{Materials}

\subsubsection{Film Selection}

Two animated cartoon movies were selected for this investigation after piloting procedure. They included Justin and the Knights of Valour, directed by Manuel Sicilia, and Pirate Fairy, directed by Peggy Holmes. The language of the movies was English and also they were shown with English subtitles. The time of each film was nearly one hour and a half. The total time duration of the two films was approximately 176 minutes and also the films had the same degree of English difficulty. The movies were selected based on the content to be interesting, the level of the films to be appropriate for learner's proficiency level (intermediate level), and lack of any offensive words or scenes. The three groups (A, B, C) of participants all watched the same movies and only the modes of captions were different. The first group (Group A) watched the two animated cartoon movies with full-captions, the second group (Group B) watched the same movies with keyword-captions, and the third group (Group C) watched them without captions.

\subsubsection{Pilot Study}

Piloting was adopted to make sure of the appropriateness of the listening materials (two animated cartoon movies in this study). A total of 15 students with characteristics similar to those of the target groups were chosen. The aim of piloting two animated cartoons was to make sure whether the level of these films was appropriate to the participants' proficiency level. Out of two films, one was selected randomly by the researcher and was presented to the pilot group. According to the results of the pilot study, the level of the film was approximately appropriate to the level of target groups. 


\subsubsection{Keyword Determination Procedure}

Keywords are defined as words that are important for the meaning of the sentences or paragraphs. In determination of keywords in two video clips, Guillory (1998) and Park (2004) involved five experienced lecturers of French to watch the clips, read the corresponding transcripts, and underline the words they considered important for understanding the sentences or paragraphs. Guillory's (1998) framework in the determination of keyword was as follows:

Guillory counted the underlined words and divided that count by the total number of respondents to calculate an initial percentage of selected words. Words receiving $50 \%$ or greater of the total number of underlined words were chosen as keywords. The percentage of keywords for each of the two scripts was almost identical $13.9 \%$ and $14.3 \%$ (Guillory, 1998, p. 94).

We also used the same keyword determination procedures as Guillory (1998) and Park (2004), i.e., we asked five experienced teachers of two different institutions to watch the films (two animated cartoon movies) and underlined the words they considered important for understanding the sentences. We processed their selections and found that above $80 \%$ of the keywords were selected by all five teachers. In fact important words such as nouns, verbs, adjectives and some words that their rate speed was high were chosen from the full script captions by these five teachers.

\subsection{Instruments}

The following data collection instruments were utilized in the present study:

\subsubsection{Proficiency test}

The first instrument which was used in this study was a PET, which was a standardized English proficiency test assessing general English proficiency of learners at intermediate level. The Preliminary English Test (PET) was used to select three homogeneous groups of participants who were at the same level of language proficiency (intermediate). As the focus of attention was listening, the researchers used the reading and listening parts of the PET to estimate the general proficiency of the participants and to assure the homogeneity of the participants in terms of listening and reading. Thus two sections of this test were administered to the participants including reading and listening with 60 items in general. As the reading skill could affect the result (because of the captions' availability), the participants' scores on the reading section were analyzed carefully to make sure that the students were at the same level of reading proficiency too. The first section (reading) included 35 multiple-choice questions on grammatical structures and vocabulary. The second section (listening) included 25 multiple-choice questions which had to be answered after listening to a conversation or monologue. The main aim of administering the proficiency test was to choose those students (45 students in this study) who were at the same level of language proficiency.

\subsubsection{Listening Comprehension Pre and Post tests}

A listening comprehension pre-test was administered to the participants before the treatment to check whether the participants were homogeneous in terms of listening comprehension. It was the listening part of the standardized PET test, which consisted of 25 multiple-choice questions. The learners were expected to listen to a conversation or a monologue and answer the questions. The ceiling score was 25 released by Cambridge ESOL exam (intermediate examination) for learners of English. A listening comprehension post-test (PET) was also administered at the end of the course (after 15 sessions treatment) to determine whether the participants have improved their listening comprehension. This test was similar to the pre-test in that it was the listening section of another version of standardized PET test, which consisted of 25 multiple-choice questions. The learners were expected to listen to a conversation or a monologue and answer the questions. The ceiling score was 25 released by Cambridge ESOL exam (intermediate level) for learners of English. The main justification for conducting post-test was to measure which group's (A, B, C) general listening comprehension has been affected by the treatment.

\subsection{Procedure}

First, 58 intermediate EFL learners who had enrolled in an EFL course at Iran National Language Institution in Shahindej were given a general English proficiency test (PET) to verify their homogeneity. The results were analyzed and the means and standard deviations scores calculated. Then, the scores which were not between -1 SD and +1 SD were excluded. Thus, the number of the participants was reduced to 45 . They were randomly assigned to three groups of 15 students: two experimental and one control groups. Then, in the first session of the semester a PET (listening section) was administered to the three groups as a pre-test. From the second session on, the teaching materials, apart from the usual class activities and materials included two animated cartoon movies titled" Justin and the Knights of Valour and Pirate Fairy", with English audio and subtitle.

176 minutes of two animated cartoon movies were divided into 15 sections (10-15 minutes for each session) and presented to the participants at the end of the class time. Each session lasted about one and half hour; about forty minutes of each session was allocated to the treatment. Each session was held every other day, i.e., 3 days a week. In each session before the students wanted to watch the films, the teacher gave them preview and overall information about the film and then the students were asked to watch to the films very carefully. The learners were allowed to take notes during the films viewing and also consult their dictionaries. After the time of the film in each session was finished, the teacher asked students some questions about the content of the film. All students in three groups were given a short quiz containing a few questions about the movies at the beginning of the next session. This procedure lasted 15 sessions. In group A, participants watched two animated cartoons with full -text captions, in group B, participants watched the same movies with keyword- captions, and participants in third group watched them without 
any captions.

At the end of the experiment period, to probe the effect of the treatment on general listening comprehension, the listening comprehension post-test was administered to all three groups. This test was the listening section of another version of PET. It is necessary to state that the two animated cartoon movies were piloted on other group of 15 learners before being given to the experimental groups and control group. According to the results of the pilot study, the level of films was approximately appropriate to the participants' proficiency level.

\subsection{Data Analysis}

Data analysis in this study was done quantitatively via Statistical Package for Social Sciences (SPSS). In order to answer the first and second research questions, first, both the pre and the post-tests were scored and all test results were entered into SPSS to analyze the data, and Paired sample t-test was run to examine if there was a statistically significant difference between the pre and post-test results of the two groups (Q1, Q2). In order to answer the third research question, after analyzing the scores on SPSS, one-way ANOVA procedure was used to measure the between-group mean differences. In order to do paired comparisons among the three groups, the SPSS post hoc test was used to indicate where the significant differences lie.

\section{Results and Discussion}

\subsection{Investigation of the First Research Question}

Q1: Does providing full captions for films have any significant impact on students' general listening comprehension?

Table 1. Descriptive Statistics of Listening Pretest and Posttest for Full-text Group

\begin{tabular}{lcllll}
\hline & $\mathrm{N}$ & Minimum & Maximum & Mean & Std. Deviation \\
\hline $\begin{array}{l}\text { Listening Pretest for Full-text15 } \\
\text { group }\end{array}$ & 13.00 & 26.00 & 20.8000 & 4.10922 \\
\hline $\begin{array}{l}\text { Listening Posttest for } \\
\text { text group }\end{array}$ & & 41.00 & 49.00 & 45.8667 & 2.03072 \\
\hline \begin{tabular}{l} 
Valid N (listwise) \\
\hline
\end{tabular} & 15 & & & & \\
\hline
\end{tabular}

According to the descriptive statistics in Table 1, the means of participants' scores in post-test was higher than pre-test. While the mean score of the pre-test for this group (first experimental group) was 20.80, the mean of post-test was 45.86. Thus, it indicated an increase in the mean scores from the pre-test to the post-test situations in learner's performance in listening comprehension through full captions films. But in order to see whether this increase was statistically significant, the researchers conducted a Paired sample t-test on SPSS (see Table2).

Table 2. Paired Sample t-test of Scores of each group in Pretest and Posttest

\begin{tabular}{|c|c|c|c|c|c|c|c|c|c|}
\hline & & \multicolumn{5}{|c|}{ Paired Differences } & \multirow[b]{3}{*}{$\mathrm{T}$} & \multirow[b]{3}{*}{ df } & \multirow{3}{*}{$\begin{array}{l}\text { Sig. }(2- \\
\text { tailed) }\end{array}$} \\
\hline & & \multirow[b]{2}{*}{ Mean } & \multirow{2}{*}{$\begin{array}{l}\text { Std. } \\
\text { Deviation }\end{array}$} & \multirow{2}{*}{$\begin{array}{l}\text { Std. Error } \\
\text { Mean }\end{array}$} & \multicolumn{2}{|c|}{$\begin{array}{l}95 \% \text { Confidence Interval } \\
\text { of the Difference }\end{array}$} & & & \\
\hline & & & & & Lower & Upper & & & \\
\hline$\overline{\text { Pair } 1}$ & $\begin{array}{l}\text { Listening Pretest for } \\
\text { Full-text group - } \\
\text { Listening Posttest for } \\
\text { Full-text group }\end{array}$ & -25.0667 & 3.57505 & .92307 & -27.04646 & -23.08687 & -27.156 & 14 & .000 \\
\hline Pair 2 & $\begin{array}{l}\text { Listening Pretest for } \\
\text { Keyword group - } \\
\text { Listening Posttest for } \\
\text { Keyword group }\end{array}$ & -17.33333 & 4.01189 & 1.03586 & -19.55504 & -15.11162 & -16.733 & 14 & .000 \\
\hline Pair 3 & $\begin{array}{l}\text { Listening Pretest for } \\
\text { No-text group - } \\
\text { Listening Posttest for } \\
\text { No-text group }\end{array}$ & -12.33333 & 6.29815 & 1.62617 & -15.82113 & -8.84554 & -7.584 & 14 & .000 \\
\hline
\end{tabular}

As Table 2 illustrated, there was a statistically significant increase in the full captions group after the treatment. The results of paired samples t-test indicates that the significant value (.000) was less than $\mathrm{p}<0.05$ which revealed that the difference is significant.

\subsection{Investigation of the Second Research Question}

Q2: Does providing keyword captions for films have any significant impact on students' general listening comprehension? 
Table 3. Descriptive Statistics of Listening Pretest and Posttest for Key- word Group

\begin{tabular}{lcllll}
\hline & $\mathrm{N}$ & Minimum & Maximum & Mean & Std. Deviation \\
\hline $\begin{array}{l}\text { Listening Pretest } \\
\text { Keyword group }\end{array}$ & for15 & 14.00 & 26.00 & 20.8000 & 3.42679 \\
\hline $\begin{array}{l}\text { Listening Posttest } \\
\text { Keyword group }\end{array}$ & for15 & 34.00 & 41.00 & 38.1333 & 2.16685 \\
\hline Valid N (listwise) & 15 & & & & \\
\hline
\end{tabular}

According to Table 3, the means of participants' scores in post-test was higher than pre-test, which indicated the mean score of keyword captions group in pre-test was 20.80 which increased to 38.13 in the post-test. Therefore, the results showed that providing keyword captions for films had a positive impact on Iranian EFL learners' general listening comprehension.

In order to see whether this difference was statistically significant, the researcher conducted a paired sample t-test, the results of which are presented in Table 2. Based on Table2, there was a statistically significant increase in the keyword captions group after the treatment. The results of paired sample t-test indicates that the significant value (.000) was less than $\mathrm{p}<0.05$ which revealed that the difference is significant.

\subsection{Investigation of the Third Research Question}

Q3: Which modes of captioning (full-captions, keyword captions, and no-captions) have the most significant impact on students' general listening comprehension?

As it can be seen in these Tables, the full captions group achieved the highest mean score (mean= 45.86) at the post-test following by keyword captions group (mean= 38.13) and no captions group (mean=33.86). In order to see whether or not the differences among the means of three types of captioning were statistically significant, the one-way ANOVA procedure was run. The results of the ANOVA procedure are presented in Table4.

Table 4. ANOVA on the Students' Scores of Listening Posttests

\begin{tabular}{llllll}
\hline & Sum of Squares & $\mathrm{df}$ & Mean Square & F & Sig. \\
\hline Between Groups & 1110.044 & 2 & 555.022 & 103.512 & .000 \\
\hline Within Groups & 225.200 & 42 & 5.362 & & \\
\hline Total & 1335.244 & 44 & & & \\
\hline
\end{tabular}

Table 4, clearly indicated that the difference between the means of the three groups was statistically significant. F ( 2 , $42)=103.51, p<.01$. However, in order to determine which group was superior to the others, a post-hoc was run and the results are as follows. Table 5, shows the results of multiple comparisons between two experimental groups and one control group.

Table 5. Scheffé Post hoc multiple range test for Posttest

\begin{tabular}{cllllll}
\hline (I) Group Type & (J) Group Type & \multicolumn{2}{l}{ Mean } & Difference & & \multicolumn{2}{l}{$95 \%$ Confidence Interval } \\
\cline { 3 - 7 } & & $(\mathrm{I}-\mathrm{J})$ & Std. Error & Sig. & Lower Bound & Upper Bound \\
\hline \multirow{2}{*}{ full text } & Key word & $7.73333^{*}$ & .84553 & .000 & 5.5876 & 9.8790 \\
\cline { 2 - 7 } & No-text & $12.00000^{*}$ & .84553 & .000 & 9.8543 & 14.1457 \\
\hline \multirow{2}{*}{ Key word } & full text & $-7.73333^{*}$ & .84553 & .000 & -9.8790 & -5.5876 \\
\cline { 2 - 7 } & No-text & $4.26667^{*}$ & .84553 & .000 & 2.1210 & 6.4124 \\
\hline No-text & full text & $-12.00000^{*}$ & .84553 & .000 & -14.1457 & -9.8543 \\
\cline { 2 - 7 } & Key word & $-4.26667^{*}$ & .84553 & .000 & -6.4124 & -2.1210
\end{tabular}

*. The mean difference is significant at the 0.05 level

According to Table5, the full captions group performed better than the keyword captions group and both of them significantly higher than the no-captions group. 


\section{Discussion}

The main purpose of this study was to investigate whether providing captions for films (full and keyword captions) had any impact on students' general listening comprehension, and that which types of captioning had a better effect on general listening comprehension of learners: full-captions, keyword-captions, or no-captions. In the current study, students' general listening comprehension had improved after 15 session treatment. One of the reasons was that providing three (aural, visual, and captions) channels could help in reducing the level of stress or anxiety on the part of participants or, on Krashen's words, lowering the affective filter so that the participants in the caption groups (either full or keyword captions) could take in more comprehensible input. We also should not deny the Paivio's Dual Coding Theory. In fact, the reason for significant development in general listening comprehension of the two experimental groups in comparison to control group was supported by this theory that, if information is coded in dual systems (as with captions and verbal language), the learner keeps and remembers that information more easily.

The results of the first research question in this study agree with the results of many previous studies which confirmed the positive effect that caption materials have on comprehension (Chung, 1999; Guillory, 1998; Huang \& Eskey, 1999; Latifi et al, 2011, Markham et al, 2001; Markham \& Peter, 2003). The result is also compatible with Bird \&Williams, 2002; and Vanderplank, 1988 who stated that captions may facilitate speech segmentation and decoding. On the other hand, when students watch films with full captions, because of the availability of three channels (aural, visual, and textual), their listening anxiety might be reduced and this process leads to a better listening performance and also more confidence in their listening skills. This was also affirmed by the Vanderplank (1988) and Graham (2006) who believed that captions might reduce anxiety, and thus leads to a better listening performance. Captions can increase the students' knowledge of the target language by the use of new lexicons and phrases in an appropriate context. This view is supported by Paivio (1971), Graza (1991), Krashen (1981, cited in Stewart and Pertusa, 2004) and Vanderplank (1988). Vanderplank (1988) also believe that "captions might have potential value in helping the language acquisition process, by providing language learners with the key to massive quantities of authentic and comprehensible language input"(272-273).

In relation to the second research question, it is confirmed that when students watch films with keyword captions, since keyword captions would reduce the cognitive load of reading captions and have students concentrate on spoken language , can cause the students' general listening comprehension to be improved from pre-test to post-test. Rooney (2011, cited in Yang and Chang, 2014) asserted that implementing partial captions (keyword captions) was effective but while learners performed better with $50 \%$ than $10 \%$ of the scripts, learners recommended even fewer captions at the proportion of $30 \%$ of total scripts. Guillory (1998) also suggested that keyword captions have better potential to focus listeners on listening rather than on reading off the screen. In other words, keyword captions could focus learners' processing ability on the auditory channel and thus enhance general listening comprehension.

In relation to the third research question, the results of one-way ANOVA of post-test, which were presented in Table 4, showed that there has been a significant difference among groups watching movies with different modes of captioning. Also, the results of multiple comparison of means showed that there has been a significant difference among full, keyword and no captions group concerning their performance on the post-test (Sig=.000). According to the results, full captions group has been the most effective mode of captioning in the improving general listening comprehension. The keyword caption and no captions are in the second and third stage, respectively. In other words, in this study, the participants in the full text captions group outperformed than keyword captions group, and both of them significantly acted better than the control group (no-captions). This findings were consistence with Guillory (1998) and one part of Park's (2004) findings (the effect of full captions and keyword captions on intermediate level learners' listening comprehension). In both studies the findings revealed that the full captions group and keyword captions group significantly outperformed control group.

\section{Conclusion}

The results of the present study revealed that providing captions for films, regardless of the type of captions, was effective in developing general listening comprehension of EFL students. Even though three groups made progress in their general listening comprehension at the end of the research period, the full-captions group's development was significantly higher than the other ones. In this study, the participants in the full text captions group (experimental 1) outperformed than keyword captions group and both of them significantly higher than the no-captions group.

\section{References}

Birds, S. A., \& Williams, J .N. (2002). The effect of bimodal input on implicit and explicit memory: An investigation into the benefits of within-language subtitling. Applied Psycholinguistics, 23(4), 509-533.

Borras, I., \& Lafayette, R.C. (1994).Effect of multimedia courseware subtitling on the speaking performance of college students of French. The Modern Language Journal, 78, 61-75.

Burger, G. (1989). Are TV programs with video subtitles suitable for teaching listening comprehension? Zielsprache Deutsch, 20(4), 10-13.

Carrier, K.A. (2003). Improving high school English language learners' second language listening through strategy instruction. Bilingual Research Journal, 27, 383-410.

Chung, J. (1999). The effects of using video texts supported with advance organizers and captions on Chinese college 
students' listening comprehension: An empirical study. Foreign Language Annals 32(3), 295-308.

Danan, M. (2004). Captioning and subtitling: Undervalued language learning strategies. Meta, 49(1), 67-77.

Field, J. (1998). Skills and strategies: Towards a new methodology for listening. ELT Journal, 52, 110-118.

Field, J. (2004). An insight into listeners' problems: Too much bottom-up or too-much top-down? System 32, $363-377$.

Flowerdew, J. \& L. Miller (2005). Second language listening: Theory and practice. New York. Cambridge University Press.

Froehlich, J. (1988). German videos with German subtitles: A new approach to listening comprehension development. Die Unterrichtspraxis/Teaching German, 21(2), 199-203.

Garza, T. (1991).Evaluating the use of captioned video materials in advanced foreign language learning. Foreign Language Annals, 24(3), 239-258.

Graham, S. (2006). Listening comprehension: The listeners’ perspectives. System, 34(2), 165-182.

Grimmer, C. (1992). Supertext English language subtitles: A boon for English language learners. EA Journal, 10(1), 6675.

Guillory, H.G. (1998). The effect of keyword captions to authentic French video on learner comprehension. CALICO Journal, 15(1-3), 89-108.

Huang, H., Eskey, D. (1999). The effects of closed-captioned television on the listening comprehension of intermediate English as a second language students. Journal of Educational Technology Systems, 28(1), 75-96.

Jung, E.H. (2003). The role of discourse signaling cues in second language learning comprehension. The Modern Language Journal, 87, 562-577.

Krashen, S. (1985). The inputh: Issues and implications. Halow: Longman.

Krashen, S. (1991). The Input Hypothesis: Issues and Implications. Laredo Publishing.

Latifi, M., Mobalegh, A., \& Mohammadi, E. (2011). Movies subtitles and the improvement of listening comprehension: Does it help? The Journal of Language Teaching and Learning, 1(2), 18-29.

Markham, P.L., Peter, L.A., \& McCarthy, T. J. (2001). The effects of native language vs. target language captions on foreign language students' DVD video comprehension. Foreign Language Annals, 34 (5), 439-445.

Markham, P., \& Peter, L. (2003). The influence of English language and Spanish language captions on foreign language listening/reading comprehension. Journal of Educational Technology Systems, 31(3), 331-341.

Mendelsohn, D. J. (1994). Learning to listen: A strategy-based approach for the second language learner. San Diego: Dominie Press.

Meskill, C. (1996). Listening skills development through multimedia. Journal of Educational Multimedia and Hypermedia, 5(2), 179-201.

Nunan, D. (1997). Listening in Language Learning. The Language Teacher. The Japan Association of Language Learning. 21(9), 47-51.

Paivio, A. (1971). Imagery and cognitive process. New York: Holt, Rinehart \& Winston.

Park, M. (2004). The effects of partial captions on Korean EFL learners' listening comprehension. Unpublished doctoral dissertation, University of Texas at Austin.

Roony, k. (2011). Impact of keyword caption ratio, language proficiency, and attitude on foreign language listening comprehension. Unpublished doctoral dissertation, Capella University, Minneapolis.

Stewart, M. A \& Pertusa, I. (2004). Gains to foreign language while viewing target language closed-caption films. Foreign Language Annals, 37(3), 438-443.

Taylor, S. E. (1964). Listening: What research says to the teacher? Washington, DC: National Education Association.

Thompson, I., \& Rubin, J. (1996). Can strategy instruction improve listening comprehension? Foreign Language Annals, 29,331-342.

Vandergrift, L. (2004). Listening to learn or learning to listen? Annual Review of Applied Linguistics. 24, 3-25.

Vandergrift, L. (2011). Second language listening. Presage, process, product, and pedagogy. In Hinkel, E. (ed.), Handbook of Research in Second Language Teaching and Learning, 455-471. New York/London: Routledge,

Vanderplank, R. (1988). The value of teletext sub-titles in language learning. English Language Teaching Journal, 42(4), 272-281.

Yang, J. C., \& Chang, P. (2014). Captions and reduced forms instruction: The impact on EFL students' listening comprehension. ReCALL, 26(1), 44-61. (SSCI, A\&HCI). 